\title{
Reviews
}

The Person and the Challenges

Volume 7 (2017) Number 1, p. 263-264 DOI: http://dx.doi.org/10.15633/pch.1994

Herman Lombaerts

Catholic University in Leuven, Belgium

\section{World Youth Days. A Testimony to the Hope of Young People, eds J. Stala \& A. Porębski, UPJPII, Kraków 2016}

Every World Youth Day is a great event of international potential, which gathers together, not only youngsters, but also their catechists, teachers, bishops with the Pope to celebrate the joy of faith in the Catholic community. After looking at the book's title, table of contents and then reading the Introduction and articles, it becomes clear that this book is a preparation to the World Youth Day in Kraków in 2016.

The editors (professors from two Kraków universities: the Pontifical University of John Paul II and the Jagiellonian University) managed to invite to this monograph very well known people: cardinals, archbishops, bishops, professors and experts from various disciplines. Thanks to their expertize, the reader is able to see World Youth Days in the historical, social, cultural spiritual, pedagogical, scientific and religious perspectives.

This publication, World Youth Days. A Testimony to the Hope of Young People, is worth recommending for many reasons. Firstly, it refers to the idea of Pope John Paul II to invite youth from all over the world to one place, and shows the historical aspects of WYD from Rome 1985 to Kraków in 2016. Secondly, highly competent authors have written the articles: Cardinal Stanisław Dziwisz, Cardinal Stanisław Ryłko, Archbishop Celestino Migliore, Marcello 
Bedeschi. Also many people who actively participated in organizing WYD in their own countries (Danny Casey, Thomas Rosica, Nathalie Becquart, and Paul Metzlaff) and experts who have been writing texts from the perspective of their corresponding disciplines dealt with issues related to social communication, law, ethics, geography, journalism, education, psychology, culture, anthropology and theology. An important part of this book presents the spiritual dimension of WYDs in a new context, especially as a chance for re-evangelisation and the rediscovery of the value of faith among the young.

The monograph is part of the current preparations for the World Youth Day in Krakow, and at the same time, it offers a reflection of scientists, bishops, representatives of religious organizations and organizers of WYD. It can be considered as the first comprehensive look at the phenomenon of WYD. Valuable as a historical perspective, showing the current experience of WYD (the book contains selected pictures from previous WYD), it presents contemporary young people, with special attention to their needs and expectations, including their diverse spiritual quests. The gathering of authors representing such different environments, countries and continents is an undeniable advantage of the publication. At the same time it is a strong witness of faith, hope and commitment of young Christians who, regardless their contexts of life, try to confess their belonging to Jesus Christ and the Church. This publication can be considered as the first scientific, comprehensive look at the phenomenon of WYD. The publication also draws attention to its aesthetic issue. An innovative idea of a "game" of colors referring to the colors of WYD. The attractive cover and elegant edition makes the book admirable, not only for its content, but also for the creativity of its aesthetic presentation. 